\title{
Incorporação de lama de alto forno em cerâmica vermelha
}

\section{(Incorporation of blast furnace sludge into red ceramic)}

\author{
C. M. F. Vieira, C. A. C. M. Dias, A. V. Mothé, R. Sánchez, S. N. Monteiro \\ Laboratório de Materiais Avançados - LAMAV \\ Universidade Estadual do Norte Fluminense Darcy Ribeiro - UENF \\ Av. Alberto Lamego, 2000, Campos dos Goytacazes, RJ, 28013-602 \\ vieira@uenf.br
}

\begin{abstract}
Resumo
Este trabalho tem por objetivo caracterizar um resíduo siderúrgico, a lama de alto forno, e avaliar o efeito da sua incorporação até $20 \%$ em peso nas propriedades e na microestrutura de uma massa argilosa. O resíduo foi submetido a ensaios de caracterização mineralógica, química, física e morfológica. Foram preparados corpos de prova por prensagem uniaxial a $20 \mathrm{MPa}$ para queima em forno de laboratório a $900{ }^{\circ} \mathrm{C}$. As propriedades físicas e mecânicas avaliadas foram: retração linear, absorção de água e tensão de ruptura à flexão. A microestrutura das cerâmicas queimadas foi avaliada por microscopia eletrônica de varredura. Os resultados mostraram que a lama de alto forno é constituída predominantemente de compostos de ferro e de material carbonoso. A granulometria deste resíduo é favorável à incorporação em cerâmica vermelha. Entretanto, o resíduo ocasionou um efeito deletério nas propriedades físicas e mecânicas da cerâmica queimada.
\end{abstract}

Palavras-chave: caracterização, cerâmica vermelha, lama de alto forno, microestrutura, propriedades, resíduo.

Abstract

This work has for objective to characterize a steel making plant waste, the blast furnace sludge, and to evaluate the effect of its incorporation, up to $20 \mathrm{wt} \%$, on the properties and microstructure of a clayey ceramic used for the fabrication of bricks and roofing tiles. The waste was submitted to mineralogical, chemical and physical tests. In order to determine the physical and mechanical properties such as linear shrinkage, water absorption and flexural rupture strength, specimens were prepared by uniaxial moldpress at $20 \mathrm{MPa}$ and then fired in a laboratory furnace at $900{ }^{\circ} \mathrm{C}$. The microstructure of the fired ceramics was evaluated by scanning electron microscopy. The results showed that the blast furnace sludge is predominantly composed of iron compounds and carbonaceous material. The particle size of the waste is appropriated for its incorporation into red ceramics. However, the waste incorporation resulted in deleterious effect on the physical and mechanical properties on the fired ceramics.

Keywords: characterization, red ceramic, blast furnace sludge, microstructure, properties, waste.

\section{INTRODUÇÃO}

O setor siderúrgico gera uma diversidade de resíduos sólidos, efluentes líquidos e emissões gasosas nas suas diversas etapas de processamento [1-6]. Com relação aos resíduos sólidos, pode-se destacar as escórias, pós, lamas e carepas. Dependendo do tipo de resíduo, ele pode ser retornado ao processo, como fonte de energia ou como matéria-prima para a produção de aço, ou ainda comercializado como coproduto para outras atividades industriais.

A lama de alto forno, por exemplo, é um resíduo gerado após a etapa de lavagem do gás de Alto-Forno. A reciclagem direta dos pós do alto forno é prejudicada pela presença de elementos indesejáveis tais como o zinco, chumbo e metais alcalinos [6]. Estes elementos com baixos pontos de fusão podem causar problemas operacionais interferindo nas reações que ocorrem no alto forno. Além disso, os pós podem conter elementos tóxicos como cádmio, cromo e arsênio. Uma análise de difração de raios $\mathrm{X}$ dos pós gerados do alto forno [7] indicam a existência de ferro metálico, guelenita $\left(\mathrm{Ca}_{2} \mathrm{Al}_{2} \mathrm{SiO}_{7}\right)$, magnetita $\left(\mathrm{Fe}_{3} \mathrm{O}_{4}\right)$, hematita $\left(\mathrm{Fe}_{2} \mathrm{O}_{3}\right)$, quartzo $\left(\mathrm{SiO}_{2}\right)$ e wustita $(\mathrm{FeO})$.

A Companhia Siderúrgica de Tubarão - CST, por exemplo, gera mensalmente cerca de $4.500 \mathrm{t}$ de lama de alto forno. Este co-produto é comercializado para indústrias cerâmicas de tijolos e telhas bem como para as indústrias cimenteiras [8]. Devido ao seu elevado teor de carbono, a lama de alto forno, misturada na massa cerâmica em até $10 \%$ em peso, contribui para a economia energética e para uniformizar a temperatura no forno.

A incorporação em cerâmica vermelha, atualmente, apresenta-se como uma das principais soluções tecnológicas para a disposição final de resíduos sólidos industriais e municipais. A variabilidade natural das características das argilas associada as técnicas de processamento relativamente simples e ainda a baixa performance exigida para os produtos permitem a presença de níveis de impurezas relativamente elevados. Com isso, pode-se deliberadamente incorporar 
outros tipos de materiais resultantes das mais diversas fontes de geração [9-12].

Neste sentido, este trabalho tem como objetivo caracterizar e avaliar a influência da incorporação de lama alto forno, proveniente de uma indústria siderúrgica integrada, nas propriedades e microestrutura de uma massa argilosa utilizada na fabricação de cerâmica vermelha.

\section{MATERIAIS E MÉTODOS}

Para realização deste trabalho foram utilizados os seguintes materiais: massa argilosa caulinítica [13] utilizada na fabricação de cerâmica vermelha proveniente do município de Campos dos Goytacazes, e lama de alto forno proveniente dos sistemas de limpeza dos gases do alto forno de uma indústria siderúrgica integrada.

Inicialmente o resíduo, a lama de alto forno, foi caracterizado em termos de composição mineralógica, composição química, distribuição de tamanho de partícula e morfologia. A composição mineralógica qualitativa do resíduo foi feita por difração de raios X com um difratômetro Seifert modelo URD 65, com radiação $\mathrm{Co}-\mathrm{K}_{\alpha}$. As análises termo-diferencial e diferencial termo-gravimétrica foram feitas em equipamento com módulo de análise simultâneo, modelo SDT2960 da TA Instruments. A taxa de aquecimento foi $10^{\circ} \mathrm{C} / \mathrm{min}$ com atmosfera de ar. A composição química foi determinada por fluorescência de raios X em espectrômetro Philips, modelo PX 2400. Para a determinação do carbono orgânico, foi utilizado o método calorimétrico, sendo a amostra do resíduo digerida em uma solução de dicromato de potássio e ácido sulfúrico concentrado, aquecida por 1 h a $150{ }^{\circ} \mathrm{C}$, resfriada, em seguida foi adicionado cloreto de bário para facilitar a decantação. A medida foi feita em espectrofotômetro Spekol UV VIS.

A distribuição de tamanho de partículas do resíduo foi obtida com as técnicas de sedimentação por gravimetria e peneiramento de acordo com norma técnica da ABNT [14]. A morfologia do resíduo foi avaliada por microscopia eletrônica de varredura em um microscópio Jeol modelo JSM 6460 LV, com espectrômetro de energia dispersiva acoplado, da Coppe/UFRJ.

Foram elaboradas quatro composições, correspondentes à incorporação do resíduo na massa argilosa, nos seguintes percentuais: 0, 5, 10 e 20\% em peso. Estas composições foram homogeneizadas a seco em galga misturadora de pista lisa por $30 \mathrm{~min}$.

Corpos-de-prova retangulares foram conformados por prensagem uniaxial a $20 \mathrm{MPa}$ nas dimensões 114 × $25 \times 11 \mathrm{~mm}^{3}$. Os corpos-de-prova foram inicialmente secos em estufa a $110{ }^{\circ} \mathrm{C}$ até peso constante para queima em forno de laboratório a $900{ }^{\circ} \mathrm{C}$, com taxa de aquecimento de $3{ }^{\circ} \mathrm{C} / \mathrm{min}$ e isoterma de $60 \mathrm{~min}$ na temperatura de patamar. $\mathrm{O}$ resfriamento foi feito desligando-se o forno. As propriedades físicas e mecânicas determinadas foram: retração linear de queima, absorção de água [15] e tensão de ruptura à flexão em três pontos [16].

A observação da superfície de fratura das amostras cerâmicas queimadas foi feita por microscopia eletrônica de varredura.

\section{RESULTADOS E DISCUSSÃO}

A Fig. 1 mostra o difratograma de raios $X$ do resíduo. Com relação às fases cristalinas, o resíduo é constituído predominantemente de óxidos de ferro, como a hematita, a magnetita e a wustita, de calcita e de quartzo. Estes resultados estão de acordo com a literatura [7]. Deve-se ressaltar que, devido a uma composição química complexa, que será apresentada mais adiante, podem existir outras fases cristalinas minoritárias. Um outro aspecto importante a ser discutido é a presença de finos de coque neste tipo de resíduo, conforme mencionado na literatura [6]. Entretanto, devido ao seu caráter amorfo, os finos de coque não podem ser identificados por DRX.

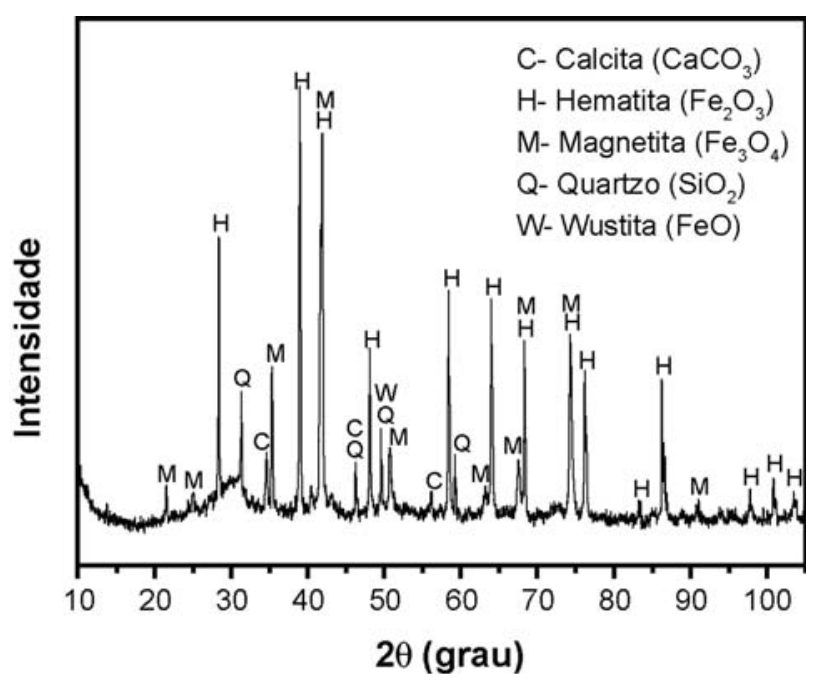

Figura 1: Difratograma de raios $\mathrm{X}$ do resíduo. [Figure 1: X-ray diffraction pattern of the waste.]

A Fig. 2 mostra as curvas de ATD/TG/DTG do resíduo. É possível observar dois picos exotérmicos bem definidos a $569,5{ }^{\circ} \mathrm{C}$ e $677,6{ }^{\circ} \mathrm{C}$, ambos associados a uma perda de massa de 6,9 e 17,7\%, respectivamente. Estas reações estão associadas à combustão dos finos de coque. A decomposição da calcita, reação endotérmica, possivelmente está sendo encoberta pela segunda reação exotérmica apresentada na Fig. 2. Este resultado comprova que este resíduo pode contribuir para a economia de energia durante a etapa de queima da cerâmica. Por outro lado, de acordo com a composição mineralógica cristalina do resíduo, Fig. 1, as reações de oxidação dos compostos de ferro não foram observadas nas curvas de ATD/TG/DTG. Possivelmente, estas reações também estejam sendo encobertas pelas reações associadas à combustão dos finos de coque.

A Tabela I mostra a composição química da massa argilosa e do resíduo. A massa argilosa apresenta uma composição típica de material caulinítico. A caulinita é o 


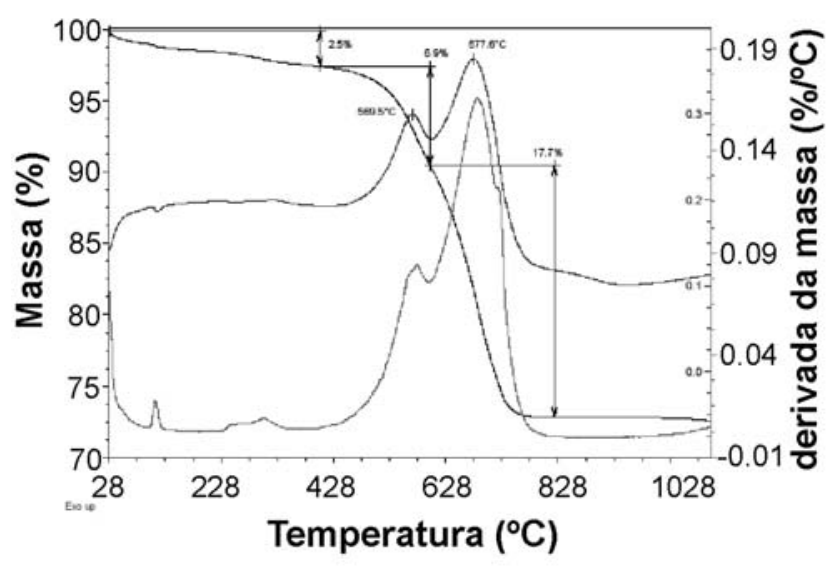

Figura 2: Curvas de ATD/TG/DTG do resíduo. Figure 2: DTA/TG/DTG curves of the waste.]

Tabela I - Composição química da massa argilosa e do resíduo lama de alto forno ( $\%$ em peso).

[Table I - Chemical composition of the clayey body and blast furnace sludge waste (wt.\%).]

\begin{tabular}{ccc}
\multirow{2}{*}{ Constituintes } & \multicolumn{2}{c}{ Matérias-primas } \\
& Massa argilosa & Lama de alto forno \\
\hline $\mathrm{SiO}_{2}$ & 48,84 & 4,94 \\
$\mathrm{Al}_{2} \mathrm{O}_{3}$ & 25,94 & 2,22 \\
$\mathrm{Fe}_{2} \mathrm{O}_{3}$ & 9,14 & 57,91 \\
$\mathrm{TiO}_{2}$ & 1,30 & 0,12 \\
$\mathrm{CaO}$ & 0,30 & 2,97 \\
$\mathrm{MgO}$ & 0,83 & 0,77 \\
$\mathrm{~K}_{2} \mathrm{O}$ & 1,91 & 0,29 \\
$\mathrm{Na}_{2} \mathrm{O}$ & 0,46 & 1,18 \\
$\mathrm{ZnO}_{\mathrm{MnO}}$ & - & 0,51 \\
$\mathrm{PnO}_{2} \mathrm{O}_{5}$ & - & 0,54 \\
$\mathrm{SO}$ & - & 0,15 \\
$\mathrm{PF}^{*}$ & - & 1,89 \\
& & \\
& 12,60 & 27,41 \\
& 0,60 & 26,22 \\
\hline
\end{tabular}

$C=$ carbono orgânico.

constituinte mineralógico principal nas argilas de Campos dos Goytacazes [17]. Observa-se um baixo percentual relativo de óxidos fundentes alcalinos bem como uma elevada perda ao fogo. A elevada perda ao fogo está associada, sobretudo, à perda de água de constituição da caulinita. Já o resíduo é constituído predominantemente de compostos de ferro, conforme indicado na Fig. 1. Observase também um elevado valor de perda ao fogo, que está associada, sobretudo, à combustão dos finos de coque. A quantidade de carbono orgânico determinada é de $26,22 \%$. Esta característica do resíduo promove calor adicional na etapa de queima da cerâmica, acarretando uma economia de gasto energético, como foi mencionado anteriormente.
A Fig. 3 apresenta a curva de distribuição de tamanho de partícula do resíduo. Observa-se uma distribuição bastante apropriada para cerâmica vermelha, que geralmente utiliza material laminado abaixo de 2-3 mm. Aproximadamente $80 \%$ das partículas do resíduo apresentam tamanho entre 0,03 a $0,08 \mathrm{~mm}$. A densidade real do resíduo, medida por picnometria, é $3,3 \mathrm{~g} . \mathrm{cm}^{-3}$.

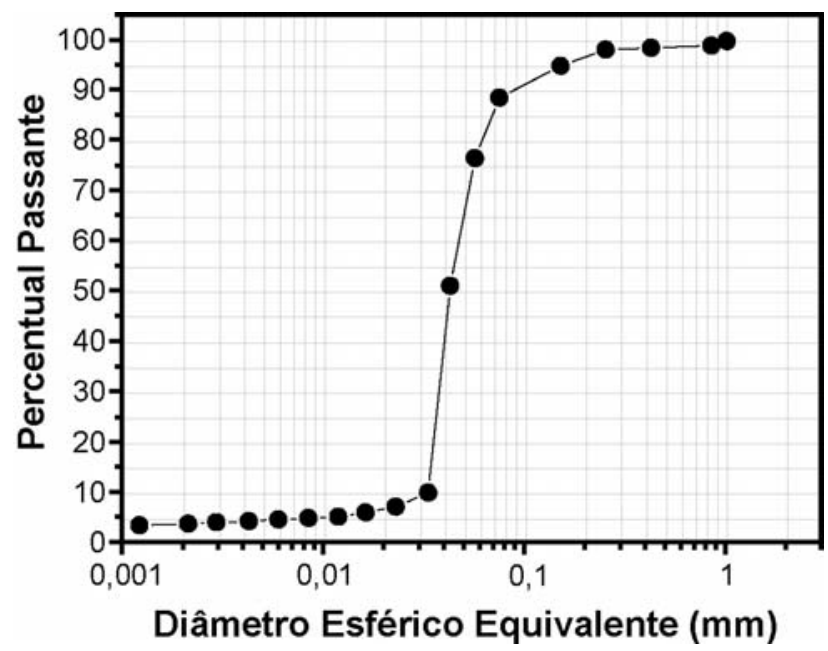

Figura 3: Curva de distribuição do tamanho de partícula do resíduo.

[Figure 3: Particle size distribution curve of the waste.]

A Fig. 4 mostra a micrografia obtida por MEV do resíduo na forma de pó. Nota-se no centro da micrografia um agregado com tamanho de aproximadamente $150 \mu \mathrm{m}$. Nesta figura são mostrados também os mapeamentos de alguns elementos identificados no espectro de EDS apresentado na própria Fig. 4. A análise da dispersão de carbono é prejudicada pela fita adesiva colada no suporte metálico da amostra. Entretanto, o mapeamento de carbono indica a presença deste elemento no agregado. O carbono está associado aos finos de coque, conforme indicado na literatura [6] e comprovado por ATD/TG, Fig. 2. O elemento ferro está associado a partículas de hematita, magnetita e wustita, conforme identificação mineralógica do resíduo, Fig. 1. O Ca está associado, sobretudo, a partículas de calcita, também identificada na Fig. 1. O Si está na forma de quartzo e possivelmente em combinação com outros elementos, como por exemplo, o Al e o próprio $\mathrm{Ca}$, formando fases complexas não identificadas por DRX.

A Fig. 5 apresenta tanto as propriedades físicas: retração linear e absorção de água, quanto à mecânica correspondente à tensão de ruptura à flexão, das cerâmicas queimadas a $900{ }^{\circ} \mathrm{C}$ em função da quantidade de resíduo incorporada na massa argilosa. É possível observar que a absorção de água da massa argilosa, 0\% de resíduo, aumenta com a incorporação de resíduo enquanto a tensão de ruptura à flexão diminui. Com $5 \%$ de resíduo 

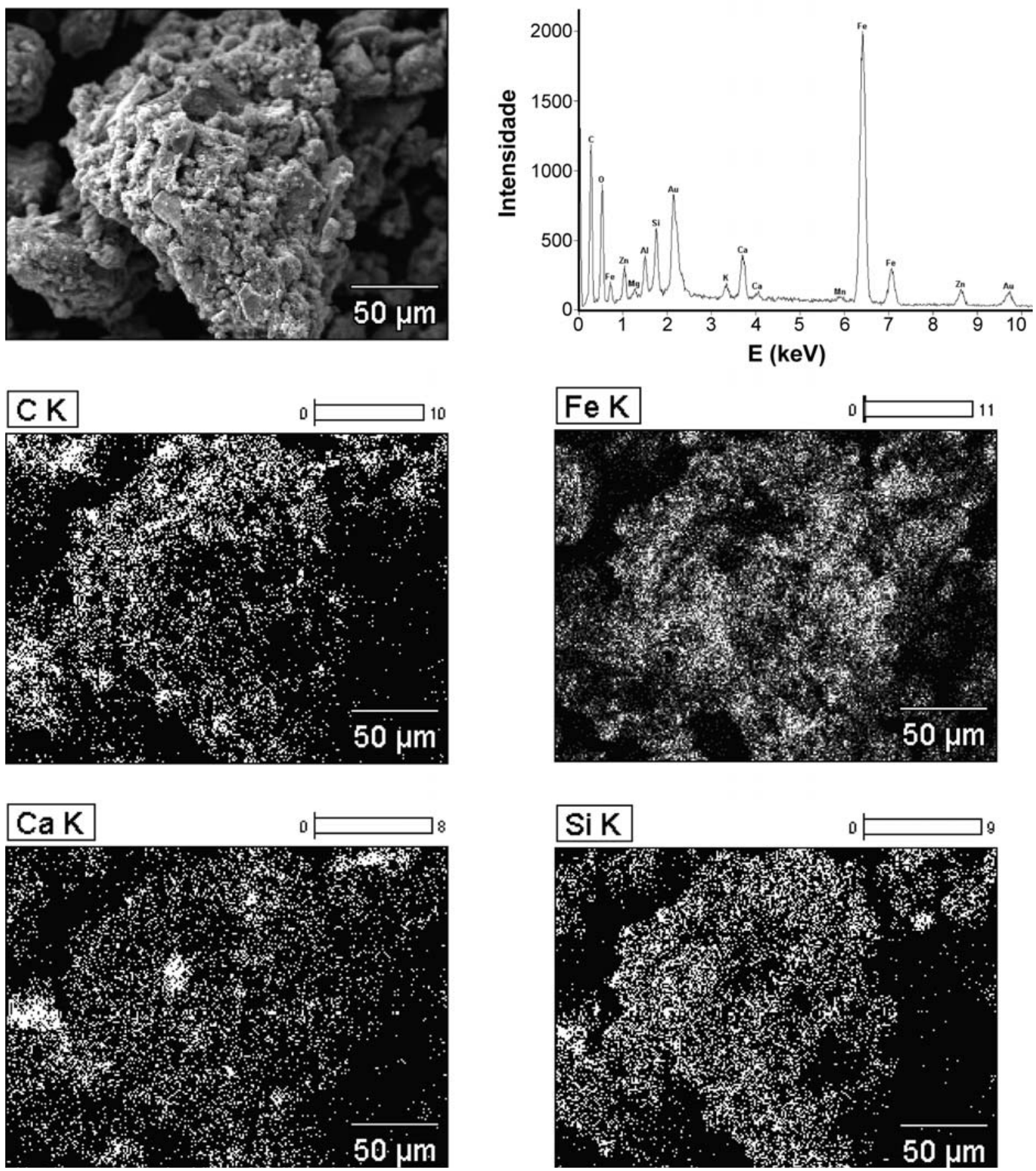

Figura 4: Micrografias obtida por MEV do resíduo com espectro de EDS e mapeamento de C, $\mathrm{Fe}, \mathrm{Ca}$ e $\mathrm{Si}$.

[Figure 4: SEM micrographs of the waste with EDS spectrum and mapping of C, Fe, Ca and Si.]

incorporado, a absorção de água aumentou em $8,2 \%$ e a resistência mecânica reduziu em $23,3 \%$. Estes resultados mostram que este tipo de resíduo é deletério para a performance técnica da cerâmica. Tal comportamento é atribuído à pouca ou à nenhuma interação física e química dos constituintes do resíduo com a matriz de alumino-silicato, proveniente das argilas. Conforme já apresentado, o resíduo é constituído predominantemente de compostos de ferro e finos de coque. Os compostos de ferro reduzidos, como a magnetita e wustita, oxidamse durante a etapa de queima, formando a hematita. A hematita permanece inerte a $900{ }^{\circ} \mathrm{C}$, contribuindo apenas para alterar a coloração da cerâmica. Além disso, os finos de coque entram em combustão acarretando mais porosidade na cerâmica. Já a retração linear de queima da cerâmica aumenta com a incorporação do resíduo. Isto também está associado à combustão dos finos de coque.

As Figs. 6 e 7 apresentam as micrografias obtidas por 


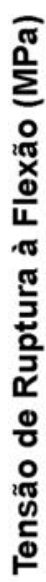

20

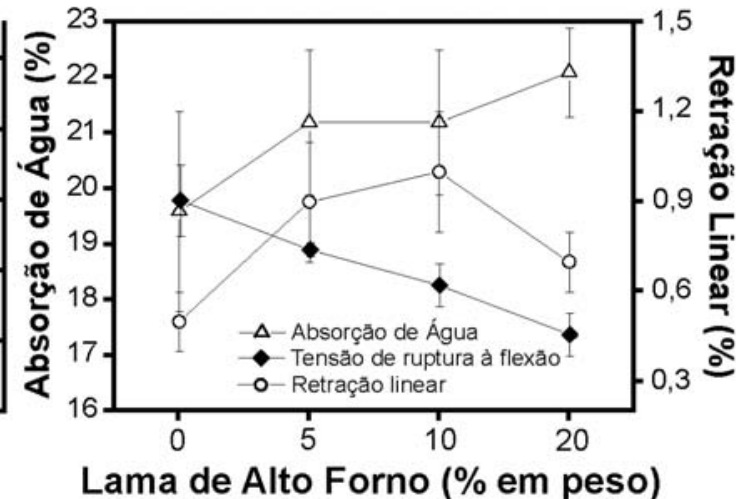

Figura 5: Propriedades de queima das cerâmicas.

[Figure 5: Fired properties of the ceramics.]
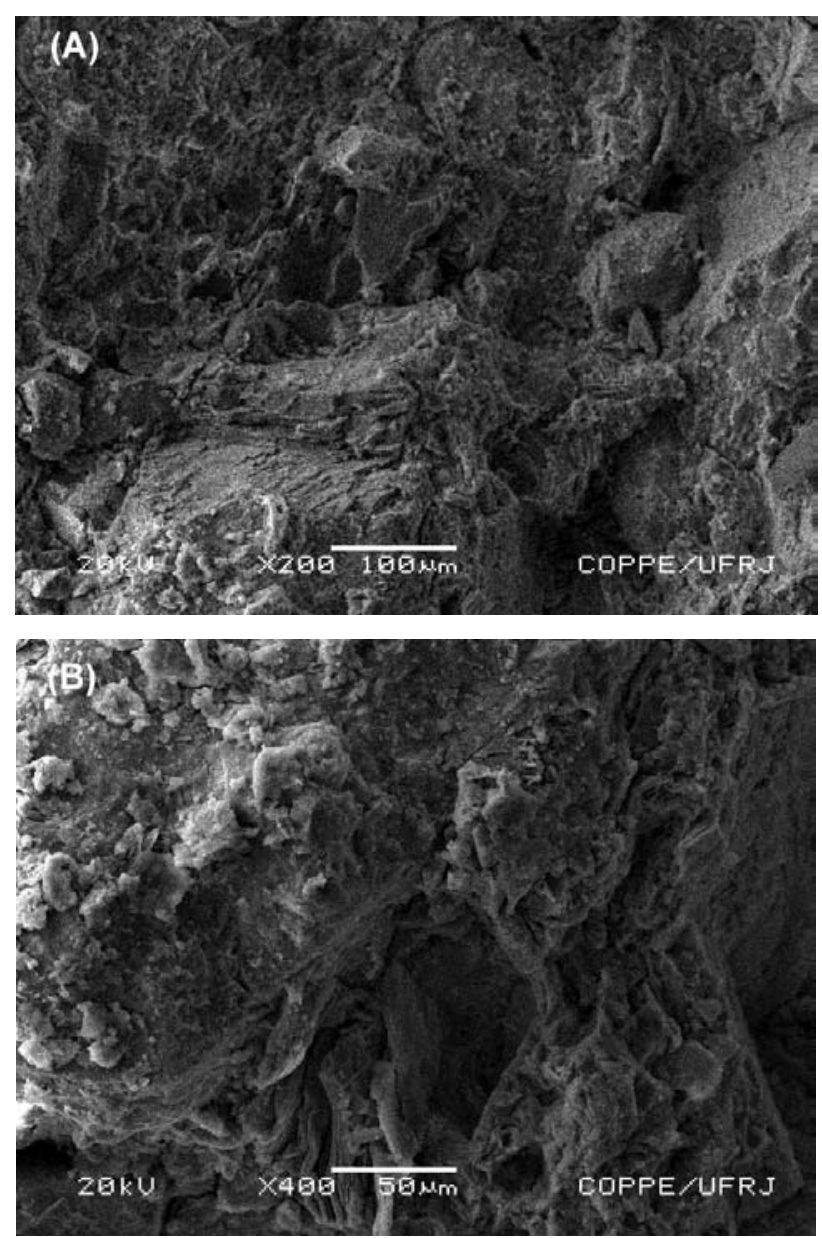

Figura 6: Micrografia obtida por MEV da região de fratura da cerâmica queimada a $900{ }^{\circ} \mathrm{C}$ sem resíduo incorporado.

[Figure 6: SEM micrograph of the fractured region of the ceramic fired at $900^{\circ} \mathrm{C}$ without incorporated waste.]

MEV da superfície de fratura das cerâmicas com 0 e $10 \%$ em peso de resíduo, respectivamente, queimada a 900 ${ }^{\circ} \mathrm{C}$. Pode-se observar que ambas as cerâmicas apresentam
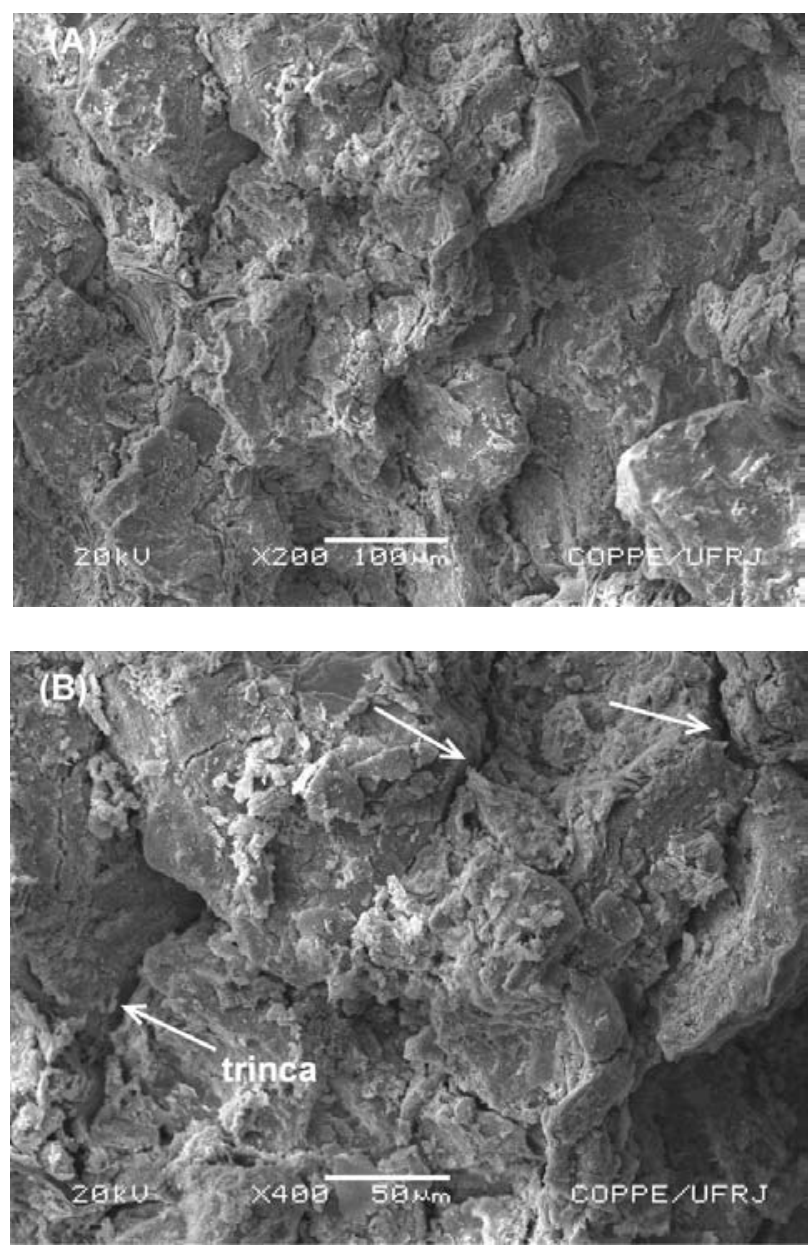

Figura 7: Micrografias obtida por MEV da região de fratura da cerâmica queimada a $900{ }^{\circ} \mathrm{C}$ com $10 \%$ em peso de resíduo incorporado.

[Figure 7: SEM micrographs of the fractured region of the ceramic fired at $900^{\circ} \mathrm{C}$ with $10 \mathrm{wt} \%$ of incorporated waste.]

uma superfície de fratura extremamente rugosa. Isto é o esperado de material caulinítico queimado a $900{ }^{\circ} \mathrm{C}$. Nesta temperatura não há formação suficiente de fase líquida para propiciar uma sinterização eficiente com alisamento da superfície e pouca quantidade de defeitos. Pode-se observar na Fig. 7 que a cerâmica incorporada com resíduo apresenta, em comparação com a cerâmica argilosa sem resíduo, Fig. 6, uma região de fratura com maior quantidade de defeitos tais como poros e trincas, conforme mostram as setas, Fig. 7b. Estes defeitos são responsáveis pela redução da resistência das cerâmicas incorporadas com resíduo.

A Fig. 8 mostra a micrografia obtida por MEV da região de fratura da cerâmica incorporada com $10 \%$ em peso de resíduo e queimada a $900{ }^{\circ} \mathrm{C}$ bem como mapeamento por EDS dos seguintes elementos: Fe, Al e Si. Nesta figura, pode-se observar no canto direito superior uma região rica em ferro possivelmente associado à hematita. É possível observar também partículas de quartzo bem distribuídas na cerâmica. 

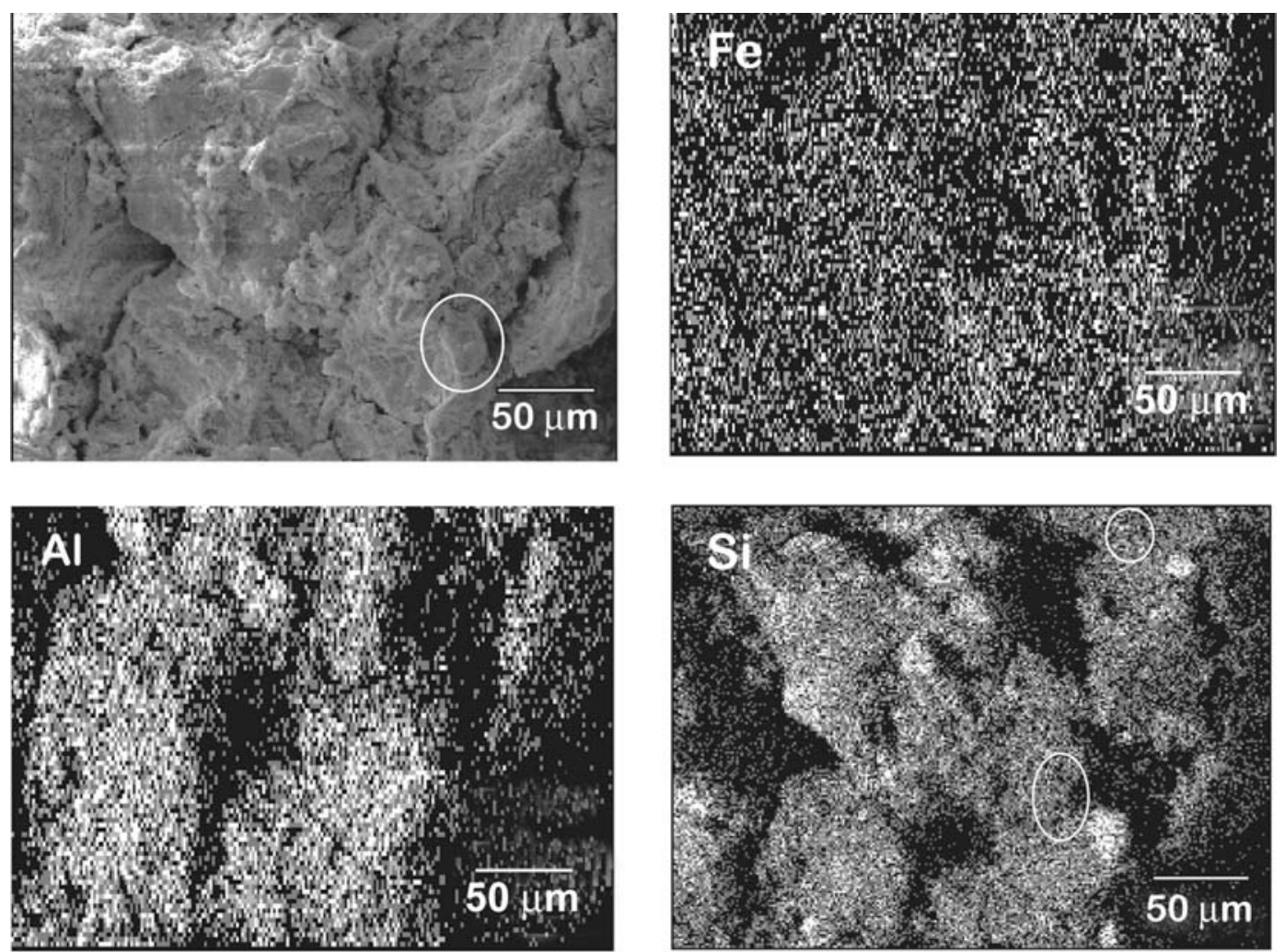

Figura 8: Micrografias obtida por MEV da região de fratura da cerâmica queimada a $900{ }^{\circ} \mathrm{C}$ com $10 \%$ em peso de resíduo com mapeamento por EDS de Fe, $\mathrm{Al}$ e Si.

[Figure 8: SEM micrographs of the fractured region of the ceramic fired at $900^{\circ} \mathrm{C}$ with $10 \mathrm{wt} . \%$ of incorporated waste with EDS mapping of Fe, Al and Si.]

\section{CONCLUSÕES}

A lama de alto forno é um resíduo constituído predominantemente por óxidos de ferro e de finos de coque. Este resíduo apresenta granulometria apropriada para a incorporação em cerâmica vermelha.

O resíduo contribuiu para aumentar a absorção de água, reduzir a tensão de ruptura à flexão e aumentar a retração linear da cerâmica queimada. Este comportamento é atribuído à composição mineralógica do resíduo. A hematita permanece inerte durante a queima e os finos de coque aumentam a porosidade da cerâmica.

Sugere-se que o resíduo seja incorporado em percentuais abaixo de 5\% em peso para minimizar os efeitos deletérios nas propriedades físicas e mecânicas da cerâmica. Por outro lado, este tipo de resíduo pode contribuir para a economia energética durante a etapa de queima da cerâmica.

\section{AGRADECIMENTOS}

À FAPERJ (Proc. E-26/151.867/2005 e E-26/170.491/ 2005), CNPq, CAPES e FENORTE/TECNORTE.

\section{REFERÊNCIAS}

[1] P. J. N. Sobrinho, J. A. S. Tenório, Anais do $55^{\circ}$ Congresso
Anual da ABM, Rio de Janeiro, RJ (2000) 2607.

[2] R. C. Nascimento, G. Lenz, D. M. dos Santos, J. D. T. Capocchi, C. Takano, M. B. Mourão, Anais do $55^{\circ}$ Congresso Anual da ABM, Rio de Janeiro, RJ (2000) 2647.

[3] I. N. Gonçalves, S. Araújo, O. Machado, Anais do $55^{\circ}$ Congresso Anual da ABM, Rio de Janeiro, RJ (2000) 2819.

[4] A. R. Correa, E. A. Villegas, Anais do $59^{\circ}$ Congresso Anual da ABM, S. Paulo, SP (2000) 2267.

[5] H. T. Makkonen, J. Heino, L. Laitila, A. Hiltunen, E. Pöyliö, J. Häkki, Resources, Conservation Recycling 35, (2002) 77.

[6] B. Das. S. Prakash, P. R. Reddy, V. N. Misra, Resources, Conservation Recycling 50, 1 (2007) 40.

[7] B. Das. S. Prakash, S. K. Biswal, P. S. R. Reddy, B. K. Mohapatra, H. K. Tripathy, Report submitted to Ministry of Steel, Bhubaneswar,India, Govt. of India Regional Research Laboratory (CSIR) (2002).

[8] http://www.cst.com.br/produtos/co_produtos/catalogo produtos/lama/cst_lama.asp, acessado em 18/01/2007.

[9] A. M. Segadães, C. Kniess, W. Acchar, N. C. Kuhnen, D. Hotza, Proc. 2004 Global Symp. Recycling, Waste Treatment and Clean Technology, Madrid, Spain (2004) 503.

[10] A. Andrés, M. Carmen Días, A. Coz, J. R. Viguri, A. Irabien, Proc. 2004 Global Symp. Recycling, Waste Treatment and Clean Technology, Madrid, Spain (2004) 171. 
[11] M. Dondi, M. Masigli, B. Fabbri, Tile \& Brick Int. 13, 3 (1997) 218.

[12] M. Dondi, M. Masigli, B. Fabbri, Tile \& Brick Int. 13, 3 (1997) 302.

[13] S. N. Monteiro, C. M. F. Vieira, Appl. Clay Sci. 27 (2004) 229.

[14] ABNT, Associação Brasileira de Normas Técnicas, NBR 7181: Determinação da Análise Granulométrica de Solos, Rio de Janeiro (1984).
[15] American Society for Testing and Materials, ASTM, Water Absorption, Bulk Density, Apparent Porosity, and Apparent Specific Gravity of Fired Whiteware Products, C 373-72 (1972).

[16] American Society for Testing and Materials, ASTM, Flexural Properties of Ceramic Whiteware Materials, C 67477 (1977).

[17] S. N. Monteiro, C. M. F. Vieira, Tile \& Brick Int. , 3 (2002) 152.

(Rec. 19/04/2007, Ac. 18/05/2007) 